\title{
Validity of additional surgical resection by comparing the operative risk with the stratified lymph node metastatic risk in patients with early gastric cancer after endoscopic submucosal dissection
}

\author{
Hidenori Akaike* (D), Yoshihiko Kawaguchi, Kensuke Shiraishi, Hiroki Shimizu, Shinji Furuya, Naohiro Hosomura,
} Hidetake Amemiya, Hiromichi Kawaida, Makoto Sudoh, Shingo Inoue, Hiroshi Kohno and Daisuke Ichikawa

\begin{abstract}
s
Background: Treatment guidelines for early gastric cancer (EGC) recommend additional gastrectomy for lesions which do not achieve curative resection after ESD, due to the potential risk of lymph node metastasis (LNM). However, many cases are found to have no LNMs, and additional gastrectomy itself can be a considerable risk especially in elderly patients.
\end{abstract}

Methods: We retrospectively stratified the risk of LNM according to the total number of four LNM risk factors (RFs) that resulted in non-curative resection for ESD in 861 EGC patients who underwent gastrectomy. Next, we compared this stratification risk to the surgical risk based on the National Clinical Database (NCD) risk calculator in 58 patients who underwent additional gastrectomy.

Results: As the total number of LNM RFs increased, the frequency of LNM also increased significantly $(0 / 1 \mathrm{RF} 0.76 \%$, 2RFs $15.08 \%$, 3RFs 33.87\%, 4RFs 50.00\%; $p<0.01$ ). The estimated frequency of LNM was found to be lower than the predicted value of in-hospital mortality rate based on the NCD risk calculator in $25.0 \%$ of 0/1RF patients.

Conclusion: These findings indicate, at least, that we should discuss the indication of additional gastrectomy individually for each patient from both perspectives of LNM and surgical risks.

Keywords: Additional gastrectomy, Early gastric cancer, Lymph node metastasis, National Clinical Database, Inhospital mortality

\section{Background}

Recently, endoscopic treatment for early gastric cancer (EGC) has been widely performed due to the improvement of diagnostic ability and progress of surgical procedures and medical devices [1]. The advent of endoscopic submucosal dissection (ESD) not only allowed accurate histopathological diagnosis but also reduced the local recurrence rate for even lesions larger than $2 \mathrm{~cm}$ and/or with ulcer scar which were

\footnotetext{
* Correspondence: hakaike@yamanashi.ac.jp

First Department of Surgery, Faculty of Medicine, University of Yamanashi, 1110 Shimokato, Chuo, Yamanashi 4093898, Japan
}

difficult with conventional endoscopic mucosal resection (EMR) [2-4].

According to the guidelines for the treatment of gastric cancer, an absolute indication of ESD against EGC is defined as being intra-mucosal carcinoma and differentiated type without ulcer formation regardless of tumor diameter and also $3 \mathrm{~cm}$ or less in intra-mucosal carcinoma and differentiated type with ulcer formation. More recently, the indication has been expanded to lesions $2 \mathrm{~cm}$ or less of intra-mucosal undifferentiated carcinoma without ulcer formation following the results of clinical trials [5-7]. On the other hand, lesions, which do not meet the criteria

(c) The Author(s). 2019 Open Access This article is distributed under the terms of the Creative Commons Attribution 4.0 International License (http://creativecommons.org/licenses/by/4.0/), which permits unrestricted use, distribution, and 
for curative resection in the histopathological examination after ESD, are deemed to have a potential risk of lymph node metastasis (LNM), and additional gastrectomy with lymph node dissection (LND) is principally recommended only in terms of metastatic risk [7]. In recent years, however, the number of elderly patients has increased, having severe comorbidities, and an additional gastrectomy itself can be a considerable risk in such patients. In fact, it must also be recognized that there are many cases without metastasis in the retrieved lymph nodes even when additional gastrectomy with LND is performed.

Shoda et al. previously reported the usefulness of stratified LNM risk factors (RFs) for patients with EGC who did not meet absolute endoscopic resection in a single institution [8]. In the first step of this study, we reanalyzed the stratified LNM RFs by adding our case series. In the second step, we calculated a 30-day surgical death and hospital death risks of cases in which additional gastrectomy with regional LND was actually performed after ESD and assessed the validity of additional gastrectomy by comparing the operative risks with the stratified LNM risk in each case.

\section{Materials and methods \\ Patients}

We retrospectively analyzed EGC patients without treatment history diagnosed by pathological examination after being diagnosed by R0 gastrectomy. All of these patients underwent LND according to the gastric cancer treatment guidelines of the Japanese Gastric Cancer Association [7]. We added 385 EGC patients who underwent gastrectomy from 2005 to 2017 at the University of Yamanashi Hospital, to the 780 EGC patients who underwent gastrectomy from 1997 to 2014 at the Kyoto Prefectural University of Medicine Hospital. In total, of these 1165 patients, 861 EGC patients (571 in Kyoto series and 290 in Yamanashi series) whose tumors did not meet the criteria for curative endoscopic resection in the gastric cancer treatment guidelines [7] were enrolled in this retrospective study. Of this study group, 743 patients underwent radical surgery without EMR/ESD and 118 patients underwent additional gastrectomy after EMR/ESD.

Next, to assess the validity of additional gastrectomy after ESD, we enrolled 58 EGC patients who underwent ESD followed by additional gastrectomy with regional LND under the diagnosis of non-curative resection from 2005 to 2017 at the University of Yamanashi hospital. Patients who underwent limited partial resection of the stomach, such as partial local resection, proximal gastrectomy, and pylorus-preserving gastrectomy, and also patients with a pathological vertical positive margin after ESD were excluded (Fig. 1).
All procedures carried out in this study were in accordance with the ethical standards of the institutional and national responsible committee on human experimentation and the Helsinki Declaration of 1964 and its later amendments or equivalents. This study was approved by the University of Yamanashi Faculty of Medicine Ethics Committee. Informed consent was obtained from all individual patients included in the study.

\section{Lymph node metastasis risk factors (LNM RFs)}

We defined the four items (see Fig. 1 for details) as LNM RFs for additional gastrectomy after EMR/ESD for EGC as reported by Shoda et al. [8] And we examined the LNM RFs and lymph node metastatic status in all of 861 patients and also examined whether the metastatic risk can be stratified by the total number of RFs as previously reported.

\section{National Clinical Database risk calculator}

National Clinical Database (NCD) is a large-scale database project in Japan and established mainly by Japanese surgical academic societies. Japanese gastroenterological surgeons register all surgical patients and their detailed patients' clinicopathological data on the website. The NCD was used to construct risk models for cancer-related surgeries, such as total and distal gastrectomy, etc., in Japanese patients, and the risk models have been already reported [9-11]. The risk models have been available as the "risk calculator" on the website, and the predicted 30-day mortality and in-hospital mortality can be calculated for each patient by entering clinical various data through the Internet. In this study, we used NCD risk calculator to evaluate surgical mortality, and compare the surgical risk with the risk of LNM in each patient with EGC.

\section{Statistical analysis}

Statistical analysis was carried out using the statistical computing software $\mathrm{R}$ version 3.4.4 ( $\mathrm{R}$ Foundation for Statistical Computing, Vienna, Austria).

Fisher's exact test, chi-square test, Mann-Whitney $U$ test, or Kruskal-Wallis test was used for statistical analyses. $p$ values lower than 0.05 were considered statistically significant in all statistical tests.

\section{Results}

\section{Stratification risk of LNM in EGC}

The mean age of the patients was 65.77 years $( \pm 11.06)$, and the gender ratio was 2.05:1 (male/female). The mean tumor size was $34.47 \mathrm{~mm}( \pm 20.54)$. The clinicopathological characteristics of patients by the total number of LNM RFs are shown in Table 1. The patients with 
EGC patients who underwent R0 gastrectomy with LND at Kyoto Prefectural University of Medicine Hospital from 1997 to 2014 at University of Yamanashi hospital from 2005 to $2017, n=1,165$

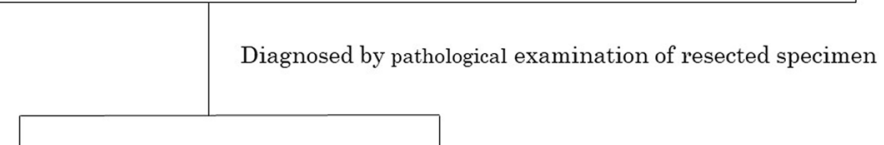

Patients who met the curative of ESD included extended indications, $\mathrm{n}=304$
Patients who did not meet absolute or extended indications of ESD, $\mathrm{n}=861$
EGC patients who underwent additional gastrectomy with LND after ESD at University of Yamanashi hospital from 2005 to 2017, n=66

\section{The risk stratification of LNM according to the} total number of LNM RFs below;

1) Deep submucosal invasion ( $>500 \mu \mathrm{m}$ from the muscularis mucoae)

2) Tumor size $>30 \mathrm{~mm}$ and macroscopic ulcer finding

3) Tumor size $>20 \mathrm{~mm}$ and undifferentiated type

4) The presence of lymphatic and/or venous invasion

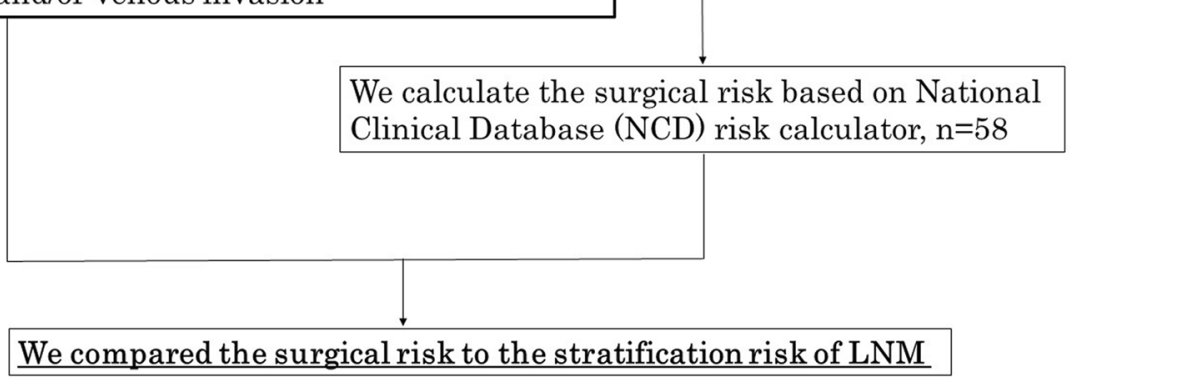

Fig. 1 Flowchart of early gastric cancer patient enrollment in this study. EGC early gastric cancer, LND lymph node dissection, LNM lymph node metastasis, RF risk factor

histologically differentiated and smaller tumor size had fewer total numbers of LNM RFs. The patients with deeper tumors, more macroscopic ulcerations, or microscopically lymphatic and/or venous invasion were also fewer LNM RFs (Table 1).

The LNM was present in $12.66 \%$ of all patients in this study $(109 / 861$, 95\% confidence interval; 10.51\%$15.07 \%)$. The frequencies of LNM stratified by the total number of four RFs are shown in Table 2. The frequency of LNM was significantly lower in patients with fewer LNM RFs. A significant correlation was found between the total number of LNM RFs and the frequency of LNM $(p<0.001)$. In particular, the frequency of LNM was far lower in patients with $0 / 1$ LNM RFs, which was $0.76 \%$ (3/396, 95\% confidence interval; 0.16-2.20), compared to the other groups (Table 2).

Comparison of the LNM risk and predicted surgical risk in cases which underwent additional gastrectomy for noncurative resection of ESD

The mean age of the patients was 67.4 years $( \pm 9.9)$, and the gender ratio was 3.83:1 (male/female). There were 35 patients who received distal gastrectomy and 23 patients who received total gastrectomy. Thirteen patients had grade 2 or more postoperative complication of the Clavien-Dindo classification (22.4\%). Table 3 shows the clinicopathological characteristics by the number of LNM RFs in these patient groups. No patients had four LNM RFs in this cohort. Patients with more LNM RFs had deeper tumors with more venous and/or lymphatic invasion.

Using the NCD risk calculator, the median in-hospital mortality was $0.5 \%$ (range; $0.1 \%-15.3 \%$ ) in this study. There was no case in which the in-hospital mortality exceeded the stratified LNM frequency in the LNM RF 2 or 3 groups. However, the in-hospital mortality was higher than the stratified LNM frequency in some cases of the LNM RF 0/1 group (Table 3).

As shown in Fig. 2, 10 cases showed higher in-hospital mortality than $0.76 \%$ which was a stratified LNM frequency in this group.

\section{Discussion}

Previous reports demonstrated that the LNM frequency of gastrectomy with LND for cases diagnosed as noncurative resection by pathological examination after 
Table 1 Comparison of clinicopathological characteristics according to the number of LNM risk factors in patients whose tumors did not meet the criteria for endoscopic resection

\begin{tabular}{|c|c|c|c|c|c|c|}
\hline & \multirow[t]{2}{*}{$n$} & \multicolumn{4}{|c|}{ Total number of items } & \multirow{2}{*}{$\begin{array}{l}p \\
\text { value }\end{array}$} \\
\hline & & $0 / 1$ & 2 & 3 & 4 & \\
\hline Total & 861 & 396 & 305 & 124 & 36 & \\
\hline Age, mean $\pm S D$ (years) & $65.77(11.06)$ & $64.69(11.36)$ & $66.14(10.72)$ & $68.01(10.84)$ & $66.72(10.30)$ & 0.024 \\
\hline \multicolumn{7}{|l|}{ Sex, $n(\%)$} \\
\hline Male & $579(67.2)$ & $253(63.9)$ & $220(72.1)$ & $85(68.5)$ & $21(58.3)$ & \multirow[t]{2}{*}{0.081} \\
\hline Female & $282(32.8)$ & $143(36.1)$ & $85(27.9)$ & $39(31.5)$ & $15(41.7)$ & \\
\hline Tumor size, mean \pm SD (mm) & $34.47(20.54)$ & $28.71(17.78)$ & $35.14(20.35)$ & $45.47(19.54)$ & $54.31(25.37)$ & $<0.001$ \\
\hline \multicolumn{7}{|l|}{ Depth of tumor, $n(\%)$} \\
\hline M & $317(36.8)$ & $237(59.8)$ & $78(25.6)$ & $2(1.6)$ & $0(0)$ & \multirow[t]{3}{*}{$<0.001$} \\
\hline SM1 & $144(16.7)$ & $118(29.8)$ & $17(5.6)$ & $9(7.3)$ & $0(0)$ & \\
\hline SM2 & $400(46.5)$ & $41(10.4)$ & $210(68.9)$ & $113(91.1)$ & $36(100)$ & \\
\hline \multicolumn{7}{|l|}{ Histological type, $n(\%)$} \\
\hline Differentiated & $359(41.7)$ & $169(42.7)$ & $142(46.6)$ & $48(38.7)$ & $0(0)$ & \multirow[t]{2}{*}{$<0.001$} \\
\hline Undifferentiated & $502(58.3)$ & $227(57.3)$ & $163(53.4)$ & $76(61.3)$ & $36(100)$ & \\
\hline \multicolumn{7}{|l|}{ Lymphatic invasion, $n$ (\%) } \\
\hline Negative & $605(70.3)$ & $365(92.2)$ & $196(64.3)$ & $41(33.1)$ & $3(8.3)$ & \multirow[t]{2}{*}{$<0.001$} \\
\hline Positive & $256(29.7)$ & $31(7.8)$ & $109(35.7)$ & $83(66.9)$ & $33(91.7)$ & \\
\hline \multicolumn{7}{|l|}{ Venous invasion, $n(\%)$} \\
\hline Negative & $706(82.0)$ & $385(97.2)$ & $227(74.4)$ & $71(57.3)$ & $23(63.9)$ & \multirow[t]{2}{*}{$<0.001$} \\
\hline Positive & $155(18.0)$ & $11(2.8)$ & $78(25.6)$ & $53(42.7)$ & $13(36.1)$ & \\
\hline \multicolumn{7}{|l|}{ Ulceration (scar), n (\%) } \\
\hline Negative & $196(22.8)$ & $104(26.3)$ & $72(23.6)$ & $20(16.1)$ & $0(0)$ & \multirow[t]{2}{*}{0.001} \\
\hline Positive & $665(77.2)$ & $292(73.7)$ & $233(76.4)$ & $104(83.9)$ & $36(100)$ & \\
\hline \multicolumn{7}{|l|}{ Preoperative ERM/ESD, n (\%) } \\
\hline Negative & $743(86.3)$ & $337(85.1)$ & $256(83.9)$ & $114(91.9)$ & $36(100)$ & \multirow[t]{2}{*}{0.012} \\
\hline Positive & $118(13.7)$ & $59(14.9)$ & $49(16.1)$ & $10(8.1)$ & $0(0)$ & \\
\hline
\end{tabular}

endoscopic resection was $3.8-8.2 \%$ [12-14]. Some endoscopists and surgeons examined whether the LNM frequency could be stratified according to several clinicopathological metastasis-related factors. In previous reports, Shoda et al. demonstrated that the LNM frequency well correlated with the number of RFs defined by them, and LNM frequency was extremely low as $0.58 \%$ in the $0 / 1 \mathrm{RF}$ group [8]. We reanalyzed the
LNM frequency with the criteria reported in a total of 861 patients treated at two different institutions and confirmed similar results, and the LNM frequency of the lowest risk group with $0 / 1 \mathrm{RF}$ was found to be as low as $0.76 \%$. Hatta et al. also reported in a multicenter collaborative study showing the risk-scoring system for LNM after ESD that does not meet the current curative criteria. In their study, they counted lymphatic invasion,

Table 2 Risk stratification of lymph node metastasis according to the total number of items that meet the indication criteria for radical gastrectomy

\begin{tabular}{llll}
\hline Total number of LNM risk factors & $n$ & LNM positive cases, $n$ & LNM rate, \% (95\% Cl) \\
\hline Total & 861 & 109 & $12.66(10.51-15.07)$ \\
Total number of items & & & \\
$\quad 0 / 1$ & 396 & 3 & $0.76(0.16-2.20)$ \\
2 & 305 & 46 & $15.08(11.26-19.60)$ \\
3 & 124 & 42 & $33.87(25.62-42.91)$ \\
4 & 36 & 18 & $50.00(32.92-67.08)$ \\
\hline
\end{tabular}


Table 3 Comparison of clinicopathological characteristics according to the number of LNM risk factors

\begin{tabular}{|c|c|c|c|c|c|}
\hline & \multirow[t]{2}{*}{$n$} & \multicolumn{3}{|c|}{ Total number of items } & \multirow{2}{*}{$\begin{array}{l}p \\
\text { value }\end{array}$} \\
\hline & & $0 / 1$ & 2 & 3 & \\
\hline Total & 58 & 40 & 14 & 4 & \\
\hline Age, mean \pm SD (years) & $67.4(9.9)$ & $66.3(10.8)$ & $68.4(6.9)$ & $74.8(7.4)$ & 0.38 \\
\hline \multicolumn{6}{|l|}{ Sex, $n(\%)$} \\
\hline Male & $46(79.3)$ & $35(87.5)$ & $8(57.1)$ & $3(75.0)$ & \multirow[t]{2}{*}{0.05} \\
\hline Female & $12(20.7)$ & $5(12.5)$ & $6(42.9)$ & $1(25.0)$ & \\
\hline Tumor size, mean $\pm \mathrm{SD}(\mathrm{mm})$ & $27.5(14.0)$ & $26.5(15.0)$ & $27.8(11.1)$ & $36.8(11.6)$ & 0.38 \\
\hline \multicolumn{6}{|l|}{ Depth of tumor, $n(\%)$} \\
\hline M & $8(13.8)$ & $8(20.0)$ & $0(0)$ & $2(1.6)$ & \multirow[t]{3}{*}{$<0.01$} \\
\hline SM1 & $22(37.9)$ & $19(47.5)$ & $2(14.3)$ & $1(25.0)$ & \\
\hline SM2 & $28(48.3)$ & $13(32.5)$ & $12(85.7)$ & $3(75.0)$ & \\
\hline \multicolumn{6}{|l|}{ Histological type, $n(\%)$} \\
\hline Differentiated & $45(77.6)$ & $29(72.5)$ & $12(85.7)$ & $4(100)$ & \multirow[t]{2}{*}{0.32} \\
\hline Undifferentiated & $13(22.4)$ & $11(27.5)$ & $2(14.3)$ & $0(0)$ & \\
\hline \multicolumn{6}{|l|}{ Lymphatic invasion, $n$ (\%) } \\
\hline Negative & $36(62.1)$ & $31(77.5)$ & $4(28.6)$ & $1(25.0)$ & \multirow[t]{2}{*}{$<0.01$} \\
\hline Positive & $22(37.9)$ & $9(22.5)$ & $10(71.4)$ & $3(75.0)$ & \\
\hline \multicolumn{6}{|l|}{ Venous invasion, $n(\%)$} \\
\hline Negative & $44(75.9)$ & $34(85.0)$ & $9(64.3)$ & $1(25.0)$ & \multirow[t]{2}{*}{0.05} \\
\hline Positive & $14(24.1)$ & $6(15.0)$ & $5(35.7)$ & $3(75.0)$ & \\
\hline \multicolumn{6}{|l|}{ Ulceration (scar), $n$ (\%) } \\
\hline Negative & $35(60.3)$ & $27(67.5)$ & $6(42.9)$ & $2(50.0)$ & \multirow[t]{2}{*}{0.24} \\
\hline Positive & $23(39.7)$ & $13(32.5)$ & $8(57.1)$ & $2(50.0)$ & \\
\hline \multicolumn{6}{|l|}{ Type of gastrectomy, n (\%) } \\
\hline DG & $35(60.3)$ & $24(60.0)$ & $9(64.3)$ & $2(50.0)$ & \multirow[t]{2}{*}{0.87} \\
\hline TG & $23(39.7)$ & $16(40.0)$ & $5(35.7)$ & $2(50.0)$ & \\
\hline \multicolumn{6}{|l|}{ Postoperative complication ${ }^{\mathrm{a}}$, n (\%) } \\
\hline Negative & $45(77.6)$ & $32(80.0)$ & $9(64.3)$ & $4(100)$ & \multirow[t]{2}{*}{0.26} \\
\hline Positive & $13(22.4)$ & $8(20.0)$ & $5(35.7)$ & $0(0)$ & \\
\hline 30-day mortality, median range (\%) & $0.3(0.1-6.3)$ & $0.3(0.1-6.3)$ & $0.3(0.1-0.4)$ & $0.5(0.2-0.6)$ & 0.11 \\
\hline In-hospital mortality, median range (\%) & $0.5(0.1-15.3)$ & $0.5(0.1-15.3)$ & $0.5(0.1-1.8)$ & $0.7(0.4-2.0)$ & 0.59 \\
\hline Stratification risk of LNM, \% (95\% Cl) & $12.66(10.51-15.07)$ & $0.76(0.16-2.20)$ & $15.08(11.26-19.60)$ & $33.87(25.62-42.91)$ & \\
\hline
\end{tabular}

${ }^{\mathrm{a} C l a v i e n-D i n d o}$ classification grade 2 or more

which was reported to be a frequent LNM factor [15-17], as 3 points and counted each of other factors associated LNM (tumor size $>30 \mathrm{~mm}$, positive vertical margin, venous invasion, and submucosal invasion $\geq 500 \mu \mathrm{m}$ ) as 1 point, stratified according to the total number, and the frequency of LNM was examined. The results of this study also showed that the LNM rate of the "low group" with the lowest risk of LNM was $2.5 \%$, extremely low [18].

In Japan, the gastrectomy-related mortality has been considered to be very low, so additional gastrectomy with LND is recommended without much consideration for cases with potential risk after non-curative
ESD. Recently, a so-called real-world Japanese data based on NCD clarified that in-hospital mortality by gastrectomy was not so low, $1.2 \%$ in distal gastrectomy [10] and $2.3 \%$ in total gastrectomy [11]. The mortality rate would not be negligible although the frequency might be relatively lower only in cases with EGC than reported. In recent years, elderly patients with EGC have been increasing due to recent aging society and popularization of medical examination in Japan. The physiological functions of various organs are generally deteriorated and comorbidities as potential surgical risk often present in elderly patients [19, 20]. These findings prompted us to examine whether 


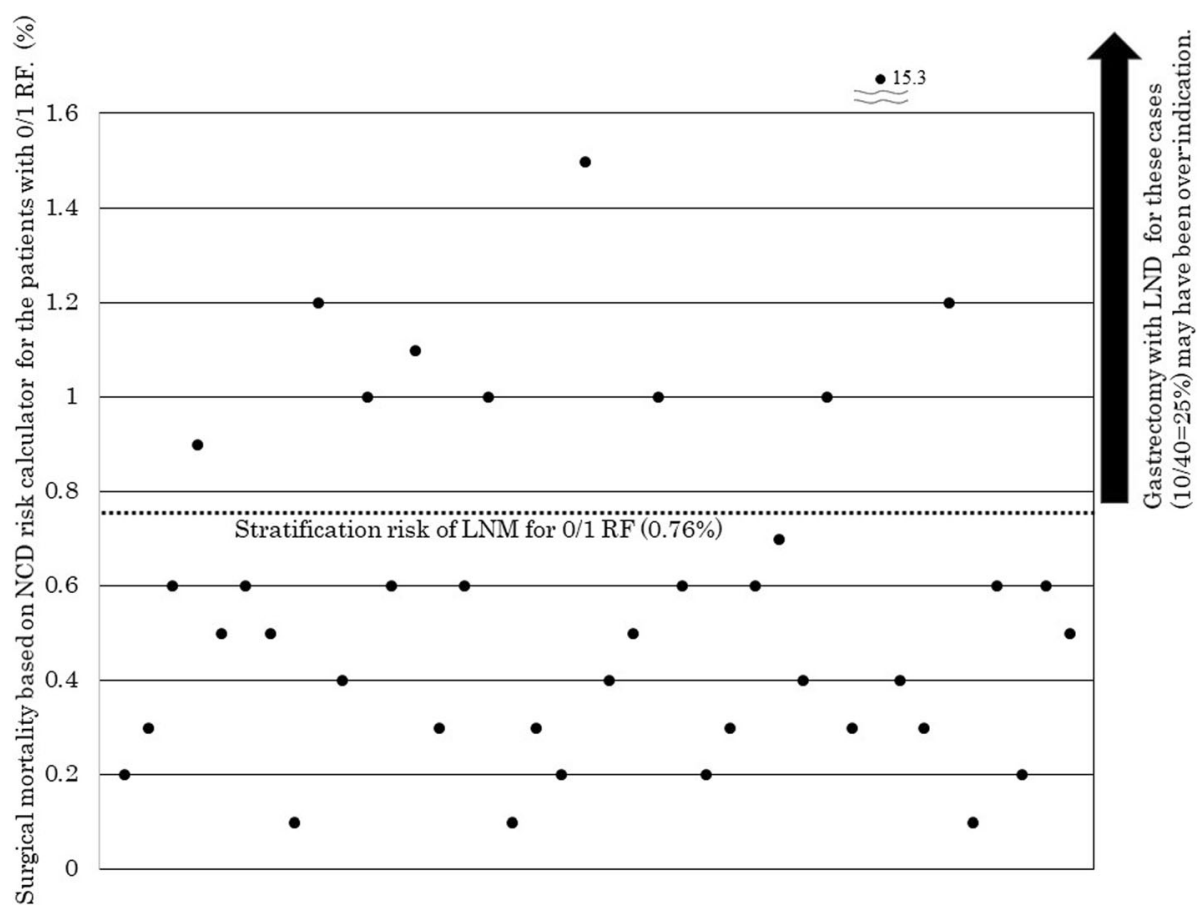

Fig. 2 Surgical mortality based on NCD risk calculator for the patients with 0/1 risk factor. RF risk factor, LNM lymph node metastasis, LND lymph node dissection

the surgical risk of additional gastrectomy may be higher than the LNM frequency in some patients with EGC after ESD. In this study, we calculated the surgical risk of each cases using the NCD risk calculator and compared the predicted mortality risk with the LNM potential risk stratified according to the number of RFs. As a result, the predicted surgical mortality was higher than the potential frequency of LNM in $25 \%$ of the case in the 0/1 RF group, which indicates the additional gastrectomy might be an over-indication. All of our case series after ESD were also applied to the "eCura system" [18] to verify the categories of LNM. As a result, $4 \%$ of patients were classified as "low group," and the LNM risk was lower than the predicted surgery-related mortality in 2.5\% (one patient) in our series. The difference of LNM risks between our results and eCura system may be due to the facts, firstly, that the evaluated risk factors of the eCura system included vertical positive margin and, secondly, that it did not include histological undifferentiated adenocarcinoma. Further nation-wide large trials should enable more accurate LNM risk diagnosis after ESD.

In this study, patients who underwent additional gastrectomy after ESD and whose surgical risk was assessed using the NCD risk calculator had no in-hospital death. However, $36.2 \%$ of patients have postoperative complications. Postoperative complications are known as recurrence and poor prognosis factors after surgery for gastric cancer [21, 22].In addition, postoperative complications were noted in 5 of 10 cases, and their surgical risk was higher than the frequency of LNM. We think that if they had not received additional gastrectomy, their prognosis might have been better.

On the other hand, 35 patients with EGC were observed which were treated by ESD without surgery under the diagnosis of non-curative resection from 2005 to 2017 at the University of Yamanashi Hospital. Among them, only one case had a recurrence in regional lymph nodes $(2.9 \%)$, and he was in the group with 2RFs. There was no recurrence in the $0 / 1 \mathrm{RF}$ group with low risk of LNM.

There are some limitations in our study. First is that our stratified LNM risk model was constructed based on clinicopathological data of EGC resected surgically. Second, the review of the comparison of LNM frequency and the surgical risk was a small-scale retrospective examination at a single facility. In the future, we might compare the prognosis of patients with higher surgical risk than LNM risk between follow-up without additional treatment group and additional gastrectomy group with regional lymph node dissection.

In conclusion, the present study clearly demonstrated that the LNM frequency could be stratified by the total number of the LNM RFs for the patients who do not meet the curative criteria after ESD. Furthermore, the risk comparison study suggested that there is a considerable number of cases in which their surgical risk was higher than 
the LNM risk among cases which additional gastrectomy was recommended for potential LNM risk. These findings indicated, at least, that we should discuss individually the indication of additional gastrectomy after ESD for each patient from both perspectives of LNM and surgical risks.

\section{Abbreviations}

EGC: Early gastric cancer; EMR: Endoscopic mucosal resection;

ESD: Endoscopic submucosal dissection; LND: Lymph node dissection; LNM: Lymph node metastasis; NCD: National Clinical Database; RF(s): Risk factor(s)

\section{Acknowledgements}

Not applicable for this manuscript.

\section{Authors' contributions}

HA performed the literature search. HA wrote the manuscript. YK, KS, and SF helped with the manuscript editing. DI provided the review concept, guided the writing, and submitted the manuscript for publication. All authors read and approved the final manuscript.

\section{Funding}

There is no funding in writing this manuscript

\section{Availability of data and materials}

Not applicable for this manuscript

\section{Ethics approval and consent to participate}

All procedures followed were in accordance with the ethical standards of the responsible committee on human experimentation (institutional and national) and with the Helsinki Declaration of 1964 and later versions. Informed consent or a substitute for it was obtained from all patients for being included in the study.

This article does not contain any studies with human or animal subjects performed by any of the authors.

\section{Consent for publication}

Not applicable for this manuscript because it does not contain personal data.

\section{Competing interests}

The authors declare that they have no competing interests.

Received: 21 April 2019 Accepted: 29 July 2019

Published online: 05 August 2019

References

1. Gotoda T. Endoscopic resection of early gastric cancer. Gastric Cancer. 2007; 10:1-11.

2. Oka S, Tanaka S, Kaneko I, et al. Advantage of endoscopic submucosal dissection compared with EMR for early gastric cancer. Gastrointest Endosc. 2006:64:877-83

3. Oda I, Saito D, Tada M, et al. A multicenter retrospective study of endoscopic resection for early gastric cancer. Gastric Cancer. 2006;9:262-70.

4. Tanabe S, Ishido K, Higuchi K, et al. Long-term outcomes of endoscopic submucosal dissection for early gastric cancer: a retrospective comparison with conventional endoscopic resection in a single center. Gastric Cancer. 2014;17:130-6

5. Gotoda T, Yanagisawa A, Sasako M, et al. Incidence of lymph node metastasis from early gastric cancer: estimation with a large number of cases at two large centers. Gastric Cancer. 2000;3:219-25.

6. Hirasawa T, Gotoda T, Miyata S, et al. Incidence of lymph node metastasis and the feasibility of endoscopic resection for undifferentiated-type early gastric cancer. Gastric Cancer. 2009;12:148-52.

7. Japanese Gastric Cancer Association. Japanese gastric cancer treatment guidelines 2014 (ver.4). Gastric Cancer. 2017;20:1-19.

8. Shoda K, Ichikawa D, Arita T, et al. Risk stratification according to the total number of factors that meet the indication criteria for radical lymph node dissection in patients with early gastric cancer at risk for lymph node metastasis. Ann Surg Oncol. 2016;23:792-7.
9. Kunisaki $\mathrm{C}$, Miyata $\mathrm{H}$, Konno $\mathrm{H}$, et al. Modeling preoperative risk factors for potentially lethal morbidities using a nationwide Japanese web-based database of patients undergoing distal gastrectomy for gastric cancer. Gastric Cancer. 2017;20:496-507.

10. Kurita N, Miyata H, Gotoh M, et al. Risk model for distal gastrectomy when treating gastric cancer on the basis of data from 33,917 Japanese patients collected using a nationalwide web-based data entry system. Ann Surg. 2015;262:295-303.

11. Watanabe $\mathrm{M}$, Miyata $\mathrm{H}$, Gotoh $\mathrm{M}$, et al. Total gastrectomy risk model: data from 20,011 Japanese patients in a nationwide internet-based database. Ann Surg. 2014;260:1034-9.

12. Oda I, Gotoda T, Sasako M, et al. Treatment strategy after non-curative endoscopic resection of early gastric cancer. Br J Surg. 2008:95:1495-500.

13. Lee J, Kim J, Kim D, et al. Is surgical treatment necessary after non-curative endoscopic resection for early gastric cancer? J Gastric Cancer. 2010;10:182-

14. Son SY, Park JY, Lee YC, et al. The risk factors for lymph node metastasis in early gastric cancer patients who underwent endoscopic resection: is the minimal lymph node dissection applicable? Surg Endosc. 2013;27:3247-53.

15. Fang $\mathrm{W}$, Huang $\mathrm{K}$, Lan $\mathrm{Y}$, et al. The risk factors of lymph node metastasis in early gastric Cancer. Pathol Oncol Res. 2015;21:941-6.

16. Hatta W, Gotoda T, Oyama T, et al. Is radical surgery necessary in all patients who do not meet the curative criteria for endoscopic submucosal dissection in early gastric cancer? a multi-center retrospective study in Japan. J Gastroenterol. 2017;52:175-84.

17. Kikuchi S, Kuroda S, Nishizaki M, et al. Management of early gastric cancer that meet the indication for radical lymph node dissection following endoscopic resection: a retrospective cohort analysis. BMC Surg. 2017;17:72.

18. Hatta W, Gotoda T, Oyama T, et al. A scoring system to stratify curability after endoscopic submucosal dissection for early gastric cancer: "eCura system". Am J Gastroenterol. 2017;112:874-81.

19. Katai $\mathrm{H}$, Sasako M, Sano T, et al. The outcome of surgical treatment for gastric carcinoma in the elderly. Jpn J Clin Oncol. 1998:28:112-5.

20. Hara H, Isozaki H, Nomura E, et al. Evaluation of treatment strategies for gastric cancer in the elderly according to the number of abnormal parameters on preoperative examination. Surg Today. 1999;29:837-41.

21. Hyashi T, Yoshikawa T, Aoyama T, et al. Impact of infectious complications on gastric cancer recurrence. Gastric Cancer. 2015;18:368-74.

22. Shimada H, Fukagawa $T$, Haga $Y$, et al. Does postoperative morbidity worsen the oncological outcome after radical surgery for gastrointestinal cancer? A systematic review of the literature. Ann Gastroenterol Surg. 2017; $1 \cdot 11-23$.

\section{Publisher's Note}

Springer Nature remains neutral with regard to jurisdictional claims in published maps and institutional affiliations.

Ready to submit your research? Choose BMC and benefit from:

- fast, convenient online submission

- thorough peer review by experienced researchers in your field

- rapid publication on acceptance

- support for research data, including large and complex data types

- gold Open Access which fosters wider collaboration and increased citations

- maximum visibility for your research: over $100 \mathrm{M}$ website views per year

At BMC, research is always in progress.

Learn more biomedcentral.com/submissions 